\title{
INOVAC̣ÃO EDUCACIONAL EM PEQUENO MUNICÍPIO - O CASO FUNDAÇÃO CASA GRANDE (NOVA OLINDA, CE, BRASIL)
}

Elie Ghanem*

RESUMO: Este artigo apresenta os resultados de um estudo de caso de inovação educacional na atuação da Organização Não Governamental Fundação Casa Grande - Memorial do Homem Kariri junto a crianças e jovens do município de Nova Olinda, CE, Brasil. O principal problema da pesquisa que este artigo visa apresentar é: que fatores se conjugam na geração de ações de inovação educacional? A hipótese examinada pela pesquisa foi a de que fatores salientes que se conjugam na geração de ações de inovação são o tempo de experiência profissional de educadores(as), a estabilidade de sua equipe, o nível de qualificação e a atuação mobilizadora de líderes da Organização. São descritos os objetivos e características da atuação da Organização e são apontadas as características de líderes, agentes e equipes. Conclui que a hipótese levantada foi confirmada.

Palavras-chave: Inovação Educacional; Reforma Educacional; Ceará.

\section{EDUCATIONAL INNOVATION IN SMALL TOWNS - THE CASE OF 'FUNDAC̣ÃO CASA GRANDE' (NOVA OLINDA, CE, BRAZIL)}

ABSTRACT: This article presents the results of an educational innovation case study on the 'Fundação Casa Grande - Memorial do Homem Kariri' Non-governmental Organization's operation with children and youngsters in Nova Olinda, State of Ceara, Brazil. The main matter of this research is: What factors are conjugated at the genesis of educacional innovation actions? The study examines the hypothesis that the proeminent factors conjugated in educational innovation generation are: length of educator's professional experience, team's stability, NGO leaders' qualification level, and mobilizing action. The NGO's objectives and operation characteristics are described. Characteristics of leaders, education agents and teams are presented. It was possible to conclude that the proposed hypothesis was confirmed.

Keywords: Educational Innovation; Educational Reform; State of Ceara

\footnotetext{
*Doutor em Educação pela Universidade de São Paulo (USP) e Professor da Faculdade de Educação da Universidade de São Paulo (USP). E-mail: elie@usp.br
} 


\section{INTRODUCุÃO}

O principal problema da pesquisa ${ }^{1}$ que este artigo visa apresentar é: que fatores se conjugam na geração de ações de inovação educacional? As inovações educacionais são tratadas em muitas investigações como reformas educacionais(ver, por exemplo, TYACK; CUBAN, 1995; FARRELL, 2000, 2001; DIDASKALOU, 2002; LAWTON, 2001; GLÓRIA; MAFRA, 2004; LEVIN, 2008; TURA; MARCONDES, 2008). Na referida pesquisa, a inovação educacional é concebida de modo completamente dissociado da atuação reformadora de governantes.

Trabalhos de significativa contribuição, a exemplo de Huberman (1976), não tomam a mesma cautela. Chegam a diferenciar os fenômenos conforme sua escala, considerando que a mudança ou inovação podem atingir apenas uma ou poucas escolas e, em grande escala, ocorrem em muitas escolas de uma província, um estado, uma região ou um país. Contudo, usualmente a inovação educacional é tratada pelo emprego intercambiável dos termos inovação, mudança, transformação e outros para designar ações que visam alterar práticas educacionais. Muito comum é fazer referência à grande escala por meio da expressão reforma educacional (CRAIG, 2001a, b; HATCH, 2001; DRAKE, SHERIN, 2006).

Em termos de alcance e intensidade da mudança planejada, Parsons e Fidler (2005) observaram que esta pode assumir tanto o caráter de mudança radical de larga escala quanto o de pequenas mudanças incrementais, assim como podem ocorrer combinações entre ambas durante períodos de equilíbrio. Sem negar a pertinência destas grandes divisões, trato de classificar as práticas educacionais tendo por base as relações entre reformadores e docentes, cujas características a análise de Torres (2000) apresenta como obstáculos à mudança educacional.

Penso que a mudança educacional deve ser o produto da convergência de práticas advindas de duas lógicas de ação diferentes: a da inovação educacional e da reforma educacional. Esta é uma mudança radical de grande escala, de caráter sistêmico.

A lógica da inovação educacional orienta práticas que estão situadas na base de sistemas escolares, às vezes em estabelecimentos individualmente considerados e outras vezes em organizações locais entendidas como associações comunitárias. Ao seguirem a lógica da inovação, as práticas 
educacionais se diferenciam do que costuma ser praticado junto a determinado grupo social em determinado lugar. Assim sendo, a inovação não se distingue por qualquer qualidade original, antes, porém, está marcada por sua diferença em relação ao que é costumeiro. Por definir-se em relação a um grupo localizado, a inovação educacional tende a ser principalmente endógena e as práticas que seguem esta orientação dependem de um elevado voluntarismo de educadores(as). Além de descontínuas no tempo, estas práticas são fragmentadas, isoladas e têm baixa visibilidade.

A reforma educacional deve ser vista como uma lógica que configura outro campo, cujas práticas não são criadas por agentes diretos de sua execução. Para estas práticas, as autoridades estatais do poder executivo e as autoridades acadêmicas das universidades fazem prescrições que as caracterizam fortemente. A orientação normativa e coerciva própria da lógica da reforma faz com que as práticas educacionais sejam muito homogêneas, tenham ampla abrangência e alta visibilidade. Tendem mais a ser muito exógenas e a contar com grande sustentabilidade, amparada por recursos orçamentários do poder público.

Sejam as práticas educacionais no âmbito da reforma sejam as circunscritas pela inovação, não há razão para que a pesquisa lhes atribua um valor positivo ou negativo a priori. As alterações que estas ações perseguem ou alcançam estão também sujeitas a juízos de valor, mas devemos concordar com Craft (2003, p. 123) quanto à necessidade de não tomá-las como ações boas ou más em si mesmas.

Tanto as ações de reforma quanto as de inovação educacional contam com muitos aspectos que requerem exame atento para que se consiga compreendê-las devidamente. Entre tais aspectos, na pesquisa aqui apresentada, elegi fatores que podem estar presentes na gênese das experiências inovadoras. Descartei os fatores referentes à atuação dos níveis hierárquicos mais elevados da administração dos sistemas escolares ou dos aparatos estatais de maneira geral, mantendo consistência com a definição de inovação que assumi.

A busca de evidências esteve subordinada à hipótese que priorizei para a pesquisa, qual seja, a de que são salientes os seguintes fatores na gênese das iniciativas de inovação educacional: a experiência profissional de docentes; a estabilidade de corpos docentes; a atuação mobilizadora de diretores(as) de estabelecimentos; e o grau de qualificação profissional de 
integrantes de organizações comunitárias. Procurei examinar a hipótese levantada efetuando o estudo de quatro casos de inovação, constituídos pelos trabalhos de ONGs (Organizações Não Governamentais) nos estados brasileiros do Amazonas, Pernambuco, Rio de Janeiro e Ceará. Os resultados deste útimo são descritos neste artigo.

Quando primeiramente levantei aquela hipótese, os fatores destacados supunham ações inovadoras em escolas regulares de educação básica. Como os estudos de casos focalizaram práticas de ONGs, tais fatores tiveram que passar por adequações. $\mathrm{O}$ tempo de docentes na profissão foi substituído pelo tempo de experiência dos(as) agentes educadores(as) das ONGs. A estabilidade destes(as) agentes na função assumiu o lugar da estabilidade de corpos docentes em escolas. A atuação mobilizadora de líderes das ONGs passou a corresponder à de diretores(as) de estabelecimentos, ao passo que o nível de qualificação profissional de líderes de associações comunitárias cedeu lugar para o nível de líderes das ONGs.

As informações utilizadas pela pesquisa foram colhidas ao longo de 2010, em visitas ao município de Nova Olinda, no sertão do Ceará. Foram obtidas principalmente por observação direta, conversas informais e entrevistas semiestruturadas junto a dirigentes, agentes educacionais e crianças e suas mães, ativas participantes das atividades da ONG, além de autoridades escolares locais.

\section{O CASO FUNDAC̣ÃO CASA GRANDE}

\section{A ONG}

A Fundação Casa Grande é uma ONG situada em Nova Olinda, um município com cerca de 13 mil habitantes no sertão do Ceará, próximo de Crato e Juazeiro, mais conhecidos. Tem uma produção agrária de milho, arroz e feijão, além de empresas extrativistas, de transformação e comerciais (a grande maioria). Conta com 17 estabelecimentos de educação infantil, 22 de ensino fundamental e 2 de nível médio. São cerca de 4,5 mil estudantes e 210 docentes. 
A sede da ONG é a casa grande de uma antiga fazenda, que, na década de 70, estava em ruínas. Em 1983, um dos netos do dono do imóvel, Alemberg Quindins, e sua esposa Rosiane Limaverde iniciaram uma pesquisa de campo coletando lendas regionais para comporem músicas sobre a pré-história do povo indígena Kariri, habitante originário. Coletaram também muitas peças de valor arqueológico. Em 1992, instalaram o Memorial do Homem Kariri na casa grande, criando a Fundação.

As atividades da Fundação se dividem em quatro programas: Memória, Artes, Comunicação e Turismo. O primeiro cataloga e expõe o acervo mitológico e arqueológico da pré-história do homem da região do Cariri. O programa de Artes se realiza a partir do Teatro Violeta Arraes - Engenho de Artes Cênicas e em laboratórios de música, cineclube, gibiteca e biblioteca. O programa de Comunicação recuperou a rádio difusora do município, "A voz da liberdade", criando o projeto Escola de Comunicação da Meninada do Sertão e os outros laboratórios de Rádio FM, TV, Editora e Internet. O programa deu origem à rede de crianças comunicadoras em língua portuguesa do Brasil, Moçambique e Angola, com apoio do Unicef. O programa de Turismo potencializa um crescente fluxo de turistas, que chegou a ser de nove vezes a população urbana de Nova Olinda. A Fundação criou junto aos pais uma cooperativa (Coopagran) para viabilizar a Casa Grande como um destino turístico e formar recepcionistas, guias de campo e relações públicas.

A Fundação é dirigida por uma assembleia de sócios, uma diretoria, um conselho fiscal (com três jovens de mais idade), um cultural (composto por cinco jovens maiores) e um científico. Os temas tratados são a organização da Casa, seu funcionamento e o "comportamento dos menores". Toda segunda-feira, há reunião pela manhã e, à tarde, distribuição das equipes para fazer as atividades. São dez gerências, cada uma com um auxiliar: DVDteca, TV, gibiteca, biblioteca, laboratório de arqueologia, editora, rádio, laboratório de Internet, memorial e teatro. Mas, cada frente tem outras atividades que atribuem responsabilidades a mais crianças: parquinho, cajueiros etc.

A frequência à Casa é gratuita e aberta a qualquer pessoa, das $8 \mathrm{~h}$ às 17h, que pode escolher uma leitura, assistir um filme, participar de peça de teatro e mesmo ajudar na gestão da Casa. Nos primórdios, o direcionamento era para jovens e não para crianças. No entanto, a Casa começou a ser muito visitada e gerar um fluxo de turistas na cidade, de modo que crianças passaram a receber as pessoas espontaneamente, explicando o que havia no interior 
do imóvel. Assim, a Casa ficou aberta funcionando com crianças como guias. As pessoas que orientam as atividades na Fundação são chamadas de formadores, consideradas ao mesmo tempo "aluno e professor", numa “escola sem sala de aula”, já que uma "aula” pode ocorrer em qualquer lugar em que estejam.

Todo dia, às $7 \mathrm{~h}$, quem frequenta a Casa faz a limpeza, varrendo, espanando, pintando ou rebocando paredes. Anualmente, organiza-se um encontro com os pais das crianças e jovens que frequentam a Casa para renovar a matrícula, uma espécie de autorização da família para participarem das atividades. Há uma ficha com fotografia e dados. Mas, mesmo sem estas formalidades, qualquer pessoa que queira pode participar. As crianças chamam as outras.

Segundo um integrante do conselho cultural, há quantidade suficiente de pessoas para se responsabilizar por todas as frentes de atuação da Fundação. São cerca de 40 crianças uniformizadas, mas, não há limite estabelecido para este número e a preocupação central é que estejam frequentando a Casa e se formem. A maioria frequenta escola pela manhã, havendo um número maior na Casa Grande no período da tarde. Pela manhã, os laboratórios ficam abertos, há poucas pessoas e mais atividades administrativas. Nas segundas-feiras, faz-se mutirão de manutenção da Casa (pintura, reparos, secar lugares em que tenha acumulado água de chuva).

A quantidade de pessoas que visitaram a Casa Grande em 2009 foi estimada em 32 mil, mas prioriza-se a "qualidade da formação" oferecida e não metas quantitativas. Uma das meninas da Casa Grande começou com a idade de 4 anos, pois ali costumava brincar. Era considerada uma casa assombrada e as crianças brincavam lá mesmo antes de ser restaurada: "[...] as crianças da cidade não tinham muito o que fazer, vinham para cá." Muitas atividades eram atraentes, como pau de sebo, campeonato de peteca e até concursos inusitados como o do menino que viesse mais limpo, mais banhado, mais cheiroso.

Um dos jovens mais experientes se concentrou no trabalho em uma área municipal com cajueiros frondosos, os mais antigos da cidade. $\mathrm{O}$ lugar pertencia à Casa Grande, a família doou à prefeitura, que nunca havia realizado nada na área. Implantou-se um projeto de educação ambiental, juntamente com um programa de esporte. Há quadras de areia para jogos, foi cavado um poço para regar as plantas e produzir mudas. É a praça mais 
utilizada da cidade e as pessoas jogam lá de manhã, à tarde e à noite. São cerca de 2 mil pessoas por mês utilizando a área. Uso que implica também incentivo à responsabilidade, pois os grupos de crianças se encarregam de emprestar a chave e a bola e devolvê-las. Não há depredação.

Para o jovem que é diretor administrativo, a Fundação se constituiu de uma maneira diferente das outras ONGs porque "foi feita mesmo para as crianças". Ao mesmo tempo, há um forte direcionamento das atividades das pessoas consideradas "meninos da Casa Grande" e controle de sua pontualidade, assiduidade e aprendizado: "Aqui, tem o que fazer. Aqui, tem o que aprender.” Aquele jovem afirmou que o seu trabalho não é voluntário nem remunerado. Ele se define como estudante: "[...] todos, na Fundação, são estudantes."

Para haver sustentação econômica, criou-se a Coopagran. A proposta é de hospedagem de turistas em pousadas familiares, nas quais se convive com uma família e se compartilha a mesma alimentação. Do montante obtido, $80 \%$ ficam com a família. Dos outros $20 \%$, metade vai para a Coopagran e 10\% para um fundo de educação, que paga o transporte de jovens da Fundação que estudam em nível superior. Além disto, a Fundação mantém parceria com o Canal Futura de TV e com o Centro Cultural do Banco do Nordeste para a produção de vídeos. Os meninos aprendem a fazer iluminação de shows, a produzir espetáculos, a gerenciar uma instituição e, pela parceria com o Sesc (Serviço Social do Comércio), encontram colocação para o trabalho de gerenciar o teatro e outras atividades culturais. Somam-se a estes mecanismos as bolsas de estudos, que obtêm recursos como rubrica de alguns projetos.

Durante os primeiros cinco anos, a Fundação recebia apenas uma doação mensal de cem reais. Trabalhavam somente Alemberg e Rosiane, que também doavam cem reais para pagar energia elétrica e manter uma senhora "olhando os meninos", uma adulta responsável. A ideia inicial era de um museu aberto à visitação durante o dia, com um vigia noturno, uma pessoa para fazer a limpeza e uma recepcionista. Muitas crianças brincavam em frente e, às vezes, a vizinhança chamava a polícia para tirá-las porque brigavam muito e diziam palavrões. Deste modo, brincando na Casa Grande, não sofriam mais aquelas ameaças. Foi colocada música durante os jogos e se reduziram os palavrões e as brigas. 
Como não havia fornecimento de água para a Casa, os meninos começaram a levar água, a aguar e varrer o chão, a tomar a iniciativa de coordenar campeonatos como de pipa e de pião e de receber visitantes do memorial. Tudo isto ocorreu sob normas de convivência e funcionamento estabelecidas e zeladas pelas pessoas adultas: "Existia uma meninada que levava a nossa linguagem para os meninos. E os outros meninos também mandavam de lá o que eles queriam. Eram os embaixadores entre a gente e os meninos."

\section{Ideias de crianças}

Todo o trabalho edificado pela Fundação foi consequência de levar em consideração ideias de crianças. Até que chegasse a primeira equipe de televisão em Nova Olinda, ninguém sabia o que era uma câmera filmadora. As crianças se interessaram e pediram "uma TV” para Alemberg. Ele conseguiu verba para comprar uma câmera, dois super-VHS e dois aparelhos de TV. A partir daí, começou a haver produção de vídeo. Uma pessoa adulta fez voluntariamente a formação de uma criança de 12 anos e esta começou a formar as outras. O gerente da TV da Casa Grande tinha 18 anos quando aprendeu edição de vídeo com um menino de 12 anos: “[...] o mais novo aprende com o mais velho, o mais velho aprende com o mais novo; o mais velho aprende com uma pessoa que não é da Casa Grande, mas, está visitando, tem uma coisa a ensinar."

No laboratório de conteúdo, há o contato com obras de grandes artistas, lendo e assistindo. No laboratório de produção, o conteúdo é "digerido", criando-se algo a partir do que foi conhecido. Deste modo, faz-se a ligação entre estes laboratórios, a DVDteca e o laboratório de TV.

\section{As escolas comuns}

Há escolas privadas e públicas em Nova Olinda. A Fundação já reuniu diretores das escolas e ofereceu o seu espaço para uso educacional. Profissionais e estudantes de todas frequentam a Casa Grande. Diretores de escolas rurais enviam ofícios à Secretaria Municipal de Transportes solicitando veículos para conduzir estudantes para participarem de atividades, por exemplo, uma aula de arqueologia visitando o Memorial, ou assistir a 
um vídeo relacionado a um tema abordado na escola. Algumas escolas não têm parquinho e organizam visitas para utilizar o da Casa Grande.

O gerente da TV Casa Grande começou a frequentá-la com 8 anos de idade, convidado por um amigo da mesma idade que, ali, fazia um programa de rádio sobre reggae. Este amigo fazia o programa sozinho e também o ensinou a fazer, operando a mesa de som, escolhendo repertório e fazendo a locução. Segundo aquele gerente, a Fundação é como uma "escola da vida", na qual contam com formação ampla e variada, nos aspectos familiar, intelectual e mesmo finanças pessoais. Formação que possibilita "a gente ter condição de fazer o que a gente pensa.". Comparando com a escola convencional, aponta que, nesta, não são oferecidas condições para produzir arte, tal como um vídeo, uma trilha sonora ou a capa de um DVD. Há meninos da Casa Grande que, tendo que fazer um trabalho de escola, produzem um vídeo documentário e apresentam: "É como se estivessem trazendo novos ares para a escola."

Em 2009, a Fundação organizou a mostra de gibis Cariri Mostrando a Nona Arte, que contou com pessoas de alguns estados brasileiros e de Portugal. A iniciativa era aberta a docentes das escolas locais para que a aproveitassem de algum modo em suas atividades letivas, como uma contribuição da Fundação à formação docente.

Além do presidente da Fundação, pelo menos quatro jovens de mais longo engajamento que entrevistei disseram ter tido uma vida escolar acidentada, pelo fato de serem "sapecas", ou "danados" e "não gostarem de estudar". Um brigava em sala de aula, atirava pedras em janelas e portas, tocava a sineta em horários que não eram do intervalo. Ele se tornou gerente da TV Casa Grande a partir de uma oficina de uma semana com um músico de São Paulo sobre todo o processo de produção de um disco (gravação, mixagem etc.). Teve a ideia de gravar a bandinha de lata e fazer um vídeo clip. Esta bandinha é o estágio inicial para quem se torna músico, passando a fazer parte da banda Meninos da Casa Grande, que já fez um circuito de apresentações na Europa.

Um dos integrantes do conselho fiscal frequentou todas as escolas da cidade porque era "muito danado", brigava muito, era expulso de toda escola em que se matriculava, as diretoras não o queriam em suas escolas e as professoras não o queriam em suas turmas. Em vão, seus pais batiam nele por isto, dentro da própria escola, quando eram chamados. Ele não 
suportava ficar "naquele espaço quadrado". Informou também que muitos dos meninos da Casa Grande, assim como ele, eram "os mais danados" dentro da escola. Acredita que as pessoas não gostam de probições, que, "quando você conversa, tudo tem jeito" e que as crianças não obedecem à professora porque ela é simplesmente impositiva, "sem amizade" e "sem conversa". Algumas passam o dia inteiro dentro da escola e não conhecem seus alunos, pretendem "passar um conteúdo planejado" independente de isto chegar a ser aprendido.

A jovem gerente da DVDteca também falou de si mesma como uma aluna que, quando era mais nova, "era danada". Não se satisfazia com as aulas copiando coisas escritas na lousa, queria algo diferente, assistir um filme ou ouvir uma música, comentar com colegas. Mais do que na escola, aprendeu muito procurando informação na Internet. Afirmou não trocar por nada esta educação que teve e que não é apenas uma aluna que leu livros, mas, que estuda cinema, gosta de arte e comunicação: “[...] quando eu era pequena, eu entrava no museu [Memorial], quando eu via aquelas coisas falando dos índios, de casa antiga, a gente começou a se interessar. $\mathrm{Na}$ verdade, eu não aprendi a ler na escola, foi na Casa Grande.” Ela entendeu estar aprendendo inclusive com a própria entrevista que me concedia porque a fazia rememorar e ajudava a sua formação.

Conforme o diretor administrativo, as pessoas à frente da Casa Grande adotaram como prioridade as atividades que entendem ser extracurriculares: “[...] aquilo que a escola não tem para oferecer." As escolas que oferecem aquelas atividades são privadas e caras e, mesmo assim nem todas oferecem as atividades disponíveis na Casa Grande, que envolvem"gestão para aprender a fazer fazendo". Ele tem uma "mágoa" de a escola "prender o aluno entre quatro paredes" e aprecia haver pessoas de escolas, casos isolados, que usam muito a Casa Grande para atividades extracurriculares. Para ele, o professor é a mais nobre das profissões e a escola deveria ser um lugar mágico, mas, diferentemente da Fundação, não é atraente para as crianças. Ele pensa que seria preciso reformular a instituição escolar e que a Fundação não tem competência e condições para fazer isto.

Inclusive Alemberg, o fundador, não gostava da escola: “[...] eu era um péssimo aluno em nota, mas, eu era um ótimo aluno quando as professoras iam promover eventos na escola. Aquela escola de estudar, fazer a prova e tirar nota eu sempre fui ridículo.” Ele disse ainda ter dificuldade 
de leitura, ler mais gibis do que livros e ter sua formação literária advinda de estudar música.

Algumas dificuldades se manifestaram quando as crianças passaram a se dedicar mais às atividades extracurriculares nos laboratórios da Casa Grande, que foi acusada de desviar as crianças dos estudos levando a notas baixas. Conforme Alemberg, a escola era desinteressante e as crianças se dedicavam mais à Casa Grande porque eram elas que a pintavam e a escola não as deixava nem escolher a cor da tinta. Elas administravam a Casa.

As iniciativas da Fundação incluíram seminários com o magistério, por exemplo, sobre arqueologia na Chapada do Araripe e sobre patrimônio (em parceria com o Iphan-Instituto do Patrimônio Histórico e Artístico Nacional) e a mostra internacional de quadrinhos. Fez-se também um projeto chamado Cinema Temático, no qual todas as turmas de todas as escolas públicas foram assistir filmes e tratar da importância do cinema na formação cultural da comunidade.

\section{Autonomia e disciplina}

São principalmente crianças que cuidam da Casa Grande, colocam-na em funcionamento e dela se utilizam. Não se ouvem gritos nem se veem adultos controlando condutas. Antes das $7 \mathrm{~h}$ da manhã, elas já estão varrendo e limpando a Casa. Depois, pegam gibis ou livros para ler, vídeos para assistir, vão fazer algo nos laboratórios, produzir um vídeo ou um programa de rádio, compor uma trilha sonora ou desenhar um gibi. Outras vão brincar no parquinho ou tocar na bandinha de lata.

Certamente, na Casa Grande, há crianças que xingam as outras e fazem bagunça. As pessoas adultas e as crianças mais velhas serenamente as repreendem e prescrevem as condutas consideradas corretas. O controle disciplinar é conjugado com o incentivo à criação e a atribuição de responsabilidades. A editora, por exemplo, foi proposta para funcionar como uma editora de verdade, tendo por meta produzir um gibi mensal sobre lendas da região e projetos da Fundação e publicar outro gibi mantido em parceria com o Centro Cultural Banco do Nordeste, uma sinopse em quadrinhos dos espetáculos exibidos no Centro.

Quanto ao preenchimento dos postos de gerência, a gerente da editora afirmou que, na Casa Grande, as coisas "acontecem naturalmente", 
desde que a pessoa chega e vai participando das atividades. Se a criança desenha, praticará desenho, se for um músico, dedicar-se-á à área de música. Muitas vezes, as pessoas descobrem sua preferência na própria Casa Grande, passando pelos diferentes laboratórios: “[...] eu não sabia desenhar, não gostava de desenhar e participei dessa oficina, com S., uma jovem da Fundação, eu fui descobrindo que eu gostava de desenhar."

Em reuniões, trata-se das nomeações para os cargos de gerentes e são considerados os nomes de pessoas que mostram maior afinidade e envolvimento com a área de cada gerência. Quem decide sobre quem ocupará cada gerência são as pessoas mais antigas da Fundação, em reuniões com Alemberg. As pessoas cogitadas para os cargos são consultadas sobre se acreditam ter condições de ocupá-los e se aceitam. Quando mais de uma pessoa pleiteia o cargo, nomeia-se uma gerente e uma auxiliar. Esta pode substituir o gerente quando este passa a ocupar outra gerência. Alemberg é quem decide em última instância, após consulta ampliada de opiniões. As pessoas começam a trabalhar em seus postos e contam com apoio das mais antigas, que as orientam.

Durante a pesquisa, eu fiquei hospedado em uma pousada familiar, a casa de uma das cooperadas da Coopagran, mãe de um dos "meninos da Casa Grande". Ela afirmou que seu filho não a obedece, mas, obedece Alemberg. A mãe manda o filho chegar à escola às $18 \mathrm{~h}$ e ele vai para a academia fazer exercícios físicos naquele horário, indo à escola somente depois.

Diferentemente, a gerente da DVDteca declarou ser muito obediente à mãe. Mesmo quando considera que sua mãe não está certa, questiona, mas, procura obedecer. Em sua casa, a obediência é devida, caso contrário, o filho terá que abandonar a casa: "[...] enquanto estiver ali, quem manda sou eu', minha mãe diz.”. Não adianta reclamar e, se resmungar, é pior. Se alguém quiser ir a outra cidade próxima e a mãe não permitir, se resmungar, a proibição se torna mais severa: “[...] mas, ela está certa [...] eu acho que a pessoa tem que ter medo da mãe, do pai."

Para que seja obedecida na condição de gerente da DVDteca, ela pode permitir ou não que uma criança empreste um DVD para assistir. Ela procura zelar pelas normas de funcionamento, por exemplo, para emprestar o DVD, a criança tem que lavar as mãos antes. Quando um grupo de crianças pede empréstimo, aquelas que lavaram as mãos fazem o controle do grupo, 
instando para que as demais também lavem. A autoridade da gerente não é afrontada pelas crianças e seu exercício é deliberadamente demarcado: "Para que eles vejam que você está ali no lugar de estar falando aquilo, de estar exercendo aquela função, de estar falando daquela forma com eles. Não de forma ignorante, mas da forma com que eles entendam." Esta hierarquia e normas são operantes porque é muito raro aplicar a punição de suspensão de uma criança por desobediência.

Os "meninos da Casa Grande" são cerca de 40 crianças e jovens uniformizados. Seus encargos são estabelecidos em uma grande reunião, na qual Alemberg, Rosiane e o diretor administrativo opinam sobre como cada pessoa está se desenvolvendo e são distribuídas responsabilidades. A distinção implica prestígio e correspondentes expectativas da população local. Elas ganham uniforme segundo o seu desempenho. Todas, de qualquer idade e com qualquer tempo de participação na Casa Grande, encarregam-se de tarefas de limpeza (varrer, passar pano). O empenho das mais novas é observado pelas mais velhas, que decidem se as primeiras merecem vestir o uniforme. Os aspectos observados são de engajamento, que inclui assiduidade e bom desempenho escolar: "[...] só participa quem estiver matriculado na escola e estiver tirando notas boas. Se tem um menino daqui que tira nota vermelha, ele é suspenso."

Uma pessoa se torna gerente quando mostra que procura aprender e se desenvolver, com a seriedade esperada geralmente em empresas, nas quais é preciso ser "um bom trabalhador", conhecer o assunto, ser pontual e assíduo. A gerente da DVDteca assumiu, antes, o cargo de gerente do Memorial com 10 anos de idade: "[...] ensinando para os meninos da minha mesma idade, foi uma novidade assim pra mim. Só que foi super bom eu ter sido gerente com 10 anos porque eu pude aprender, eu pude mostrar que eu era capaz.” Durante os 13 anos em que ela participou da Fundação, nunca ninguém questionou alguma nomeação feita.

Não há uma duração definida para o mandato. Não há disputa pelo cargo de gerente porque cada pessoa se interessa por algo diferente (uma por cinema, outra por música, outra por desenho etc.) e porque "é um trabalho que a gente não recebe dinheiro, mas, a gente recebe educação e formação.”. Segundo a gerente da DVDteca, especialmente para as meninas, este engajamento é uma alternativa numa cidade pequena, que não oferece opções: “[...] ou tem uma festa de forró por aí, ou você vai prá beira da 
pista descer e subir. É isso que tem aqui. É uma cidade pequena, a pessoa não tem escolha." Ela é a única filha que estuda em nível superior, seus familiares dão muito valor a isto e a consideram um exemplo a ser seguido pelos irmãos. De seu ponto de vista, em família grande e cidade pequena, a mulher casa logo ou vai trabalhar como empregada doméstica para ajudar na renda da família. Segundo Alemberg, a mãe faz tomar conta dos meninos mais novos, limpar e varrer a casa, cozinhar. Quando é de noite, seguem o ditado do sertão: "[...] prenda suas éguas que meus cavalos estão soltos."

No entanto alguns pais queriam proibir seus filhos de frequentar a Casa, entre os quais estava o pai do diretor administrativo. Este perguntou ao seu pai se ele tinha condição de dar o que a Casa Grande oferecia e conseguiu o consentimento. Segundo declarou, são os filhos que levam os pais e não o inverso: “[...] quando o pai trazia o filho para a Casa Grande, ele não ficava, ele não se adaptava."

Um membro do conselho fiscal tornou-se diretor de meio ambiente na Fundação porque se identificou com o assunto e acredita que ser diretor é assumir responsabilidade em uma área com a qual se tem afinidade. A dedicação é intensa, um integrante do conselho cultural passa a maior parte do tempo na Casa Grande, na qual, a cada quinzena, dormem dois adultos como medida de segurança. Ele chega às $7 \mathrm{~h}$ da manhã, faz o seu programa de rádio até as $9 \mathrm{~h}$, edita vídeos até $11 \mathrm{~h}$, almoça até $12 \mathrm{~h} 30$, quando volta para fazer limpeza com os meninos. Às 16h30, vai para casa tomar banho para ir à faculdade. Aquele conselheiro afirmou que, na Casa Grande, há meninos "sapecas" à semelhança de como ele foi nas escolas comuns. Há brigas, por exemplo, porque um quer andar na bicicleta e o dono não quer deixar, ou casos em que uma criança toma o brinquedo de outra ou fala palavrões, o que é proibido pelo artigo $2^{\circ}$ do Estatuto ("Fica permanentemente proibida a utilização de palavrões, incentivos ao consumo de drogas, uso de violência e músicas de sentido pejorativo”).

Quando ocorrem condutas reprováveis, as crianças envolvidas são repreendidas pelos "formadores", que são pessoas mais velhas. Se não acatam os "formadores", são ordenadas a voltarem para casa (suspensão) e só poderem retornar à Casa Grande no dia seguinte. Os pais são chamados para conversar. Vários depoimentos asseguraram que estes procedimentos de manutenção de um padrão de condutas funcionam. 
As práticas de repreensão mantêm constância e, havendo obediência, há a perspectiva de participar dos laboratórios, o que é muito apreciado. Quando a criança aceita não falar palavrão, pode ir ao programa de rádio ouvir música ou falar para a comunidade. A rádio alcança toda a cidade e tem um programa infantil diário (Submarino Amarelo), com crianças de 1 a 12 anos de idade. Eu entrei no estúdio um momento e oito crianças desta faixa etária estavam conduzindo o programa sozinhas.

De acordo com a gerente do laboratório de arqueologia, para fazer parte da Casa Grande, "a vassoura é a porta de entrada" e, dos pequenos aos maiores, todas as pessoas fazem toda a limpeza. Para Alemberg, a vassoura simboliza a percepção do outro, no sentido de notar que alguém limpando deve ser ajudado. Aquela gerente é a coordenadora da manutenção da Casa, controla entrada e saída de materiais de limpeza em uma planilha e afirmou que a intenção é valorizarem mais o espaço. Não há um momento determinado para a criança receber uniforme e isto depende de esta demonstrar bom envolvimento com as atividades, responsabilidade e "vontade": "Alemberg dá o uniforme, diz as palavras para a gente valorizar o uniforme [...] chama todo mundo na roda, aí, ele chama o nome da pessoa, a pessoa se levanta, vai lá.” Ela se tornou gerente do laboratório a partir de acompanhar escavações arqueológicas. Além de fazer escavações, cataloga peças, aprende a limpá-las, os significados dos nomes e recebe crianças no laboratório. O aprendizado envolve também leituras especializadas e é orientado por Rosiane.

O diretor administrativo da Fundação é "o mais velho menino da Casa Grande”, pensa ter sido um menino irriquieto, que gostava de criar coisas e não de ficar parado. Era "muito danado", saía de casa escondido para tomar banho nos açudes sem saber nadar, pulava o muro para jogar bola quando o responsável pela quadra não dava a chave, mexia com os guardas da prefeitura na rua e atirava pedras neles. $\mathrm{Na}$ escola, brigava muito, atirava giz nos colegas, no entanto, tinha bom desempenho nas notas no ensino fundamental. Em casa, ouvia conselhos de seu pai e, na Casa Grande, os de Alemberg. Disse ter sido recepcionista e que, lá,todos são, conversam com as pessoas, fazem contatos, intercâmbio e amigos: “[...] o cargo mais alto aqui da Casa Grande é o de recepcionista [...]". Fez também programas de rádio, foi gerente da DVDteca e da TV.

De acordo com o diretor administrativo, algumas pessoas aproveitam mais as oportunidades. Ele distinguiu "o menino da Casa Grande” do 
"menino que vem para a Casa Grande". O primeiro estaria "fazendo a coisa funcionar, sendo formado para ser um gestor, para ser um líder.”. O outro seria "atendido" pelo primeiro. Numa adaptação, deixará de ser um menino que "vem só pra brincar" e passará a vir "pra aprender". Reconheceu que há uma hierarquia de autoridade na qual a presidência (Alemberg) está no topo, seguida do diretor administrativo e dos gerentes. Se as condutas das crianças destoam das regras estabelecidas, elas são admoestadas e, se insistem, são pressionadas a deixar a Casa.

$\mathrm{Na}$ visão daquele diretor, o caráter inovador da experiência se deve à "filosofia da Casa", segundo a qual são feitas atividades e, destas, surgem necessidades às quais se procura responder com uma criação. $\mathrm{O}$ teatro foi construído porque se exibiam filmes na rua, com uma televisão de 14 polegadas e com caixa de som, a assistência sentada em um tronco de árvore e as peças de teatro eram encenadas na calçada. Os programas de rádio eram emitidos por um autofalante; surgiu a necessidade de uma rádio FM. Uma menina fazia revistinha pintando na mão; surgiu a necessidade da editora.

\section{Líderes, agentes e equipes}

Uma líder destacada em alta qualificação na Casa Grande é Rosiane. Nos primórdios, o memorial esteve ameaçado de ser fechado pelo Iphan porque não dispunha de um técnico para responder pelas peças da coleção. Foi necessário formar alguém para isto. Tendo Rosiane se formado em história na Urca (Universidade Regional do Cariri), fez mestrado na Universidade Federal do Piauí, que atua no sítio arqueológico de São Raimundo Nonato, no Museu do Homem Americano. Rosiane deu andamento ao seu curso de doutorado na Universidade de Coimbra. Já vinha exercendo a função de arqueóloga e tinha sido chamada para lidar com um cemitério indígena encontrado durante escavações de uma empresa de água. Assim, a Casa Grande recebeu o título de Casa do Patrimônio da Chapada do Araripe, é guardiã de todo o patrimônio material e imaterial da Chapada.

Quatro exemplos de pessoas que exercem liderança na Casa Grande mostraram pouca idade, significativamente longa experiência e não muito elevado nível de escolaridade. O diretor administrativo, 26 anos, juntou-se à Casa Grande em 1997, aos 9 anos de idade. É “o mais velho menino da 
Casa Grande”, tem o ensino médio completo. Veio da zona rural, seu pai tinha uma pequena propriedade, era vaqueiro e agricultor. O gerente da TV Casa Grande, 22 anos, era estudante de $5^{\circ}$ semestre do curso de Construção Civil, na Urca, em Juazeiro. Queria um curso da área de artes, mas não havia. Pensou em aproveitar o conhecimento em construção nas atividades de escavação arqueológica que estão relacionadas à Fundação. A gerente da editora, 18 anos, fazia Artes Visuais na Urca (estava sem aulas porque faltavam professores para o seu curso). A gerente da DVDteca, 18 anos, estudava Artes Cênicas na Urca. Começou a frequentar a Casa Grande com cinco anos de idade, quando participou de uma iniciação artística com aulas sobre recepção de visitantes à Fundação. Tornou-se recepcionista até os 10 anos e, depois, passou a ser gerente do memorial. A gerente do laboratório de arqueologia, 19 anos, pretendia cursar geografia na Urca. Começou a participar com 9 anos de idade, pois ia brincar ali de modo intermitente. Aos 12 anos, tornou-se "menina da Casa Grande", em seguida, auxiliar e, depois, gerente.

Em idade, trajetória profissional, origem e tempo de experiência, estes exemplos se diferenciam do idealizador da ONG, Francisco Alemberg de Souza Lima, 45 anos. O pai o fez nascer em Crato, pois isto conferia status elevado por ter sido sede do episcopado da região. Como farmacêutico, seu pai equivalia a um médico da localidade, receitava, fazia intervenções cirúrgicas, tratava de fraturas, ministrava remédios, fazia partos, tratava e extraía dentes. Era autodidata e aprendeu lendo. Mudou-se para Nova Olinda, depois, para Miranorte, Goiás (hoje, Tocantins), onde Alemberg viveu até os 18 anos. Então, foi marinheiro em Natal, retornando ao Crato em 1985. Estudou apenas até a 8 a série do nível fundamental.

No rio próximo de sua casa, Alemberg brincou, nadou e pescou. Sua diversão era o rio e jogar futebol. Com 14 anos, ele quebrou uma perna e, imobilizado, pegou o violão de um amigo, aprendeu a tocar uma música e compôs outra. Mas, suas primeiras ações em arte foram com desenho de histórias em quadrinhos e com cinema de sombras, que apresentava em casa para as crianças da vizinhança. Aprendeu a ler com as histórias em quadrinhos. Quando ia às cidades próximas, Guaraí e Paraíso, procurava a banca de revistas e encontava Roy Rogers, Paladino do Oeste, Batman, Homem Aranha, Tex e Ken Parker. Começou a fazer revistas em quadrinhos: "[...] a gente tinha uma vida cultural cheia de cinema, de revista, de música e tinha 
uma vida desportiva. A gente jogava futebol e gostava disso, ouvia os jogos pela rádio Globo."

Dando baixa na Marinha, voltou ao Crato, viveu de fazer artesanato de cabaça e corda e lecionar violão. Passou a levar mais a sério a composição e pesquisava lendas e construía instrumentos musicais durante seis meses, viajando nos meses restantes pelo Brasil com Rosiane, apresentando-se em festivais. Depois, começou a trabalhar com produção cultural junto a secretarias de cultura municipais. Foi diretor do Museu do Crato e Secretário de Cultura deste município, onde criou festivais. Voltando a Nova Olinda para promover eventos, reencontrou-se com a Casa Grande.

A confiança de adultos em relação a crianças é coerente com a infância de Alemberg. Seu pai lhe deu um quartinho no quintal para ele fazer um cinema. Pegava uma caixa, um pano branco, uma lanterna e bonecos de plástico. Fazia o cartaz e reproduzia os filmes, fazia toda a história, tocava, fazia a trilha sonora. Os meninos pagavam dez palitos de fósforo pela entrada do cinema. O "cinema" era associado à “editora", que produzia artesanalmente uma revista de esportes, com notícias dos jogos de futebol das crianças, bem como revistas em quadrinhos. Nas revistas, anunciava o "cinema", ao qual as crianças poderiam se associar, receberiam uma carteirinha com a foto desenhada e pagariam meia entrada. Esta vida cultural de sua infância foi levada para a Casa Grande.

Certa vez, Alemberg fez uma palestra para professoras na Itália. Estas lhe disseram que o delas era muito diferente do trabalho da Fundação, devido às exigências italianas de que houvesse profissionais especializados (psicólogos, pedagogos etc.) "dizendo pras crianças como é que iria ser". Ele ressaltou que, também no Brasil, o próprio Estatuto da Criança e do Adolescente aborda sempre a criança como receptora e não como produtora: "[a ideia] do atendido. Se eu não tivesse pegado numa enxada e limpado o campinho que nós limpamos, jamais eu saberia o que é construir uma área de lazer na infância, em conjunto com o grupo.”

\section{CONCLUSÃO}

Voltada para a preservação da memória, a Casa Grande foi criada como um museu aberto à visitação. Como museu, desdobra-se em um trabalho informativo, educacional, em laboratórios de criação artística e 
de comunicação midiática, assim como em pesquisa arqueológica. Nestes aspectos, a Casa Grande se assemelha a muitos museus. Seu caráter inovador está na educação que realiza, marcadamente diferente da educação familiar e da educação escolar do pequeno município de Nova Olinda. Um importante traço distintivo deste caráter inovador está no lugar central que crianças e jovens ocupam na operação da organização, na sua constante manutenção e limpeza e sobretudo nos sentidos e formas das atividades realizadas. Estas derivam fundamentalmente das aspirações, gostos e iniciativas infantis.

Não se pode dizer que a tomada de decisões sobre as principais orientações da Casa Grande seja responsabilidade direta de crianças e jovens, mas há uma dedicação deliberada das pessoas adultas em encaminhar os processos decisórios não só com base na consulta às crianças e jovens, mas também de modo a oferecer-lhes condições e estimular-lhes a responsabilidade na efetivação de ações emanadas de suas próprias motivações e preferências. Esta perspectiva se combina com o emprego frequente de aprendizado mútuo, com a alternância de papéis de ensinantes e aprendizes entre as pessoas mais novas e entre estas e as mais velhas.

Outro procedimento inovador que sobressai é o envolvimento das famílias com o conjunto do projeto por meio de uma alternativa econômica, integrada ao engajamento dos filhos na continuidade de sua própria carreira escolar.

O estudo do caso da Fundação Casa Grande, além de evidenciar suas peculiaridades como experiência inovadora, reuniu elementos acerca do tempo de experiência profissional dos(as) agentes educadores(as), da estabilidade da equipe, da qualificação e atuação mobilizadora de líderes. A hipótese em torno da qual a pesquisa se desenvolveu apontava tais fatores como salientes na gênese da iniciativa de inovação. Tendo em vista uma disposição favorável a inovar, o tempo de experiência profissional pode influir tanto sendo elevado quanto sendo reduzido. Se for reduzido, poderá implicar vínculos fracos com um trabalho sedimentado e, se for elevado, pode eliminar temores quanto a criticar modos convencionais e propor experimentações.

Duas implicações para a inovação também derivam do grau de estabilidade da equipe. Processos de entendimento e consensos quanto a ter práticas diferenciadas podem depender de uma baixa rotatividade. Mas, assim como o reduzido tempo de experiência de agentes educadores(as), a 
menor estabilidade das equipes pode significar menos compromisso com os costumes do grupo, encorajando experimentações.

O questionamento da homogeneidade com que se realizam práticas educacionais pode também advir do nível de qualificação profissional de quem exerce liderança. Ao passo que a equipe de educadores(as) pode ser ainda impulsionada a lançar-se em iniciativas inovadoras pela atuação mobilizadora de tais líderes.

Na sua origem, a Fundação Casa Grande resultou do empreendimento de um casal de músicos, pessoas que se definem exatamente pela criatividade. Ao longo de duas décadas, foi constituindo equipes com crianças que se tornaram jovens no exercício de atividades marcadas por um compromisso de tipo profissional, embora não fossem ocupações remuneradas. Deste modo, pode-se dizer que o tempo de "experiência profissional" de agentes educadores(as) é significativamente alto, bem como é alta a estabilidade de suas equipes. Por sua vez, seus principais líderes (dirigentes e gerentes de laboratórios) mostram engajamento permanente na mobilização de crianças, jovens, de mães e mesmo do pessoal que trabalha nas escolas locais. Embora poucas destas pessoas que exercem liderança tenham alta escolaridade, seu nível de qualificação é extraordinariamente alto por estar sendo continuamente incrementado na própria realização de suas atividades. Embora não pudessem estar presentes todos os fatores de inovação desde o início, uma vez que a experiência se iniciou com a própria organização, antes que esta pudesse contar com equipes, no caso da Fundação Casa Grande, a hipótese levantada pela pesquisa se confirmou, tendo sido constatada a presença dos fatores salientes de inovação por esta apontados. 


\section{REFERÊNCIAS}

CRAFT, A. The limits to creativity in education: dilemmas for the educator. British Journal of Educational Studies, Oxford, v. 51, n. 2, p. 113-127, 2003. http://dx.doi.org/10.1111/14678527.t01-1-00229

CRAIG, C. J. No satisfaction: a case of "the monkey's paw", top-down school reform, and the conduit. Curriculum Inquiry, Toronto, v. 31, n. 3, p. 341-350, 2001a. http://dx.doi. org/10.1111/0362-6784.00201

CRAIG, C. J. The relationship between and among teacher's narrative knowledge, communities of knowing, and school reform: a case of "the monkey's paw". Curriculum Inquiry, Toronto, v. 31, n. 3, p. 303-331, 2001b. http://dx.doi.org/10.1111/0362-6784.00199

DIDASKALOU, E. S. Current obstacles to change in Greek primary schools: implications for managing behaviour problems. European Journal of Education, Oxford, v. 37, n. 4, p. 473-482, 2002. http://dx.doi.org/10.1111/1467-3435.00122

DRAKE, C.; SHERIN, M. Practicing change: curriculum adaptation and teacher narrative in the context of mathematics education reform. Curriculum Inquiry, Toronto, v. 36, n. 2, p. 153-187, 2006. http://dx.doi.org/10.1111/j.1467-873X.2006.00351.x

FARRELL, J. P. Why is educational reform so difficult? Curriculum Inquiry, Toronto, v. 30, n. 1, p. 83-103, 2000b. http://dx.doi.org/10.1111/0362-6784.00155

FARRELL, J. P. Can we really change the forms of formal schooling? And would it make a difference if we could? Curriculum Inquiry, Toronto, v. 31, n. 4, p. 389-398, 2001. http:/ / dx.doi.org/10.1111/0362-6784.00204

GLÓRIA, D. M. A.; MAFRA, L. A. A prática da não-retenção escolar na narrativa de professores do ensino fundamental: dificuldades e avanços na busca do sucesso escolar. Educação e Pesquisa, São Paulo, v. 30, n. 2, p. 231-250, ago. 2004.

HATCH, T. The usual monkey business: a case of repetition and reform. A response to Cheryl Craig's 'The relationships between and among teachers' narrative knowledge, communities of knowing, and school reform: a case of 'the monkey's paw". Curriculum Inquiry, Toronto, v. 31, n. 3, p. 333-340, 2001. http:/ / dx.doi.org/10.1111/0362-6784.00200 HUBERMAN, A. M. Como se realizam as mudanças em educação: subsídios para o estudo do problema da inovação. Tradução de Jamir Martins. São Paulo: Cultrix, 1976. 121 p.

LAWTON, D. Book review "Images of educational Change", ed. H. Altrichter e J. Elliot. Buckingham: Open University Press (2000). British Journal of Educational Studies, Oxford, v. 49, n. 4, p. 446-472, 2001.

LEVIN, B. How to change 5000 schools: a practical and positive approach for leading change at every level. Cambridge: Harvard Educational Press, 2008.

PARSONS, C.; FIDLER, B. A new theory of educational change - punctuated equilibrium: the case of the internationalization of higer education institutions. British Journal of Educational Studies, Oxford, v. 53, n. 4, p. 447-465, Dec 2005. http://dx.doi. org/10.1111/j.1467-8527.2005.00306.x

TORRES, R. M. Reformadores y docentes: el cambio educativo atrapado entre dos logicas. In: CÁRDENAS, L.; RODRIGUEZ CÉSPEDES, A.; TORRES, R. M. El maestro, protagonista del cambio educativo. Bogotá: Convenio Andrés Bello; Magisterio Nacional, 2000. p. 161-312. 
TURA, M. L. R.; MARCONDES, M. I. Heterogeneidade, ciclos e a prática pedagógica. Revista Brasileira de Estudos Pedagógicos, Brasília, v. 89, n. 222, p. 242-258, 2008.

TYACK, D.; CUBAN, L. Tinkering toward utopia: a century of public school reform. Cambridge: Harvard University Press, 1995.

\section{NOTAS}

${ }^{1}$ Realizada com apoio da Fapesp (Fundação de Amparo à Pesquisa do Estado de São Paulo).

Recebido: $14 / 03 / 2012$
Aprovado: $11 / 05 / 2012$
Contato:
Universidade de São Paulo
Departamento de Filosofia da Educação e Ciências da Educação
Av. da Universidade, 308
CEP 05508-040
São Paulo, SP
Brasil

